\title{
Supporting Professional Learning in a Massive Open Online Course
}

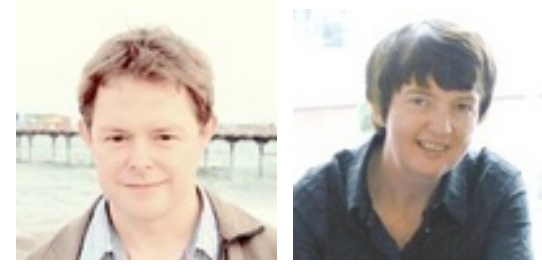

Colin Milligan and Allison Littlejohn

Glasgow Caledonian University, United Kingdom

\section{Abstract}

Professional learning, combining formal and on the job learning, is important for the development and maintenance of expertise in the modern workplace. To integrate formal and informal learning, professionals have to have good self-regulatory ability. Formal learning opportunities are opening up through massive open online courses (MOOCs), providing free and flexible access to formal education for millions of learners worldwide. MOOCs present a potentially useful mechanism for supporting and enabling professional learning, allowing opportunities to link formal and informal learning. However, there is limited understanding of their effectiveness as professional learning environments. Using self-regulated learning as a theoretical base, this study investigated the learning behaviours of health professionals within Fundamentals of Clinical Trials, a MOOC offered by edX. Thirty-five semi-structured interviews were conducted and analysed to explore how the design of this MOOC supported professional learning to occur. The study highlights a mismatch between learning intentions and learning behaviour of professional learners in this course. While the learners are motivated to participate by specific role challenges, their learning effort is ultimately focused on completing course tasks and assignments. The study found little evidence of professional learners routinely relating the course content to their job role or work tasks, and little impact of the course on practice. This study adds to the overall understanding of learning in MOOCs and provides additional empirical data to a nascent research field. The findings provide an insight into how professional learning could be integrated with formal, online learning.

Keywords: MOOCs; massive open online courses; professional learning; self-regulated learning 


\section{Introduction}

Professional work and learning are deeply intertwined. Where learning at work takes the form of formal, deliberate training or development it is easy to identify as learning'. By contrast, non-formal learning embedded in everyday work activities is more difficult to recognise as learning' (Eraut, 2000). Yet both forms of learning, formal and nonformal, are important for the development of different forms of expertise. Theoretical expertise may be learned through deliberate effort, while practical expertise is learned 'on the job'. Therefore the interweaving of professional practice and professional learning offers a new basis for how we think about work, education, and learning (Beckett \& Hager, 2002).

Conventional forms of professional training, such as workshops or courses with alternate periods of formal instruction and practical experience, often do not fully exploit the linkages between professional practice and professional learning. This means the existing knowledge, professional and personal networks that each professional brings to their learning setting remains under-exploited (Littlejohn, Milligan, \& Margaryan, 2011). The near ubiquity of computer technology provides great potential for networked learning that promotes and supports connections between learners and resources (J ones \& Steeples, 2002). However, professional learning has (largely) not taken advantage of the opportunities networks afford around how people collaborate to learn, how feedback can be exploited, and the multiple ways in which people and resources can be brought together to enhance learning (Littlejohn \& Margaryan, 2013).

One of the most visible forms of networked learning are massive open online courses (MOOCs): online courses aimed at open participation and access via the web and usually delivered free of charge, lowering social, cultural and geographic barriers to participation. MOOCs draw on the ubiquity of the web, spanning boundaries and bringing people with diverse experiences together. Even where courses are formal, the 'open' and online format offers a useful approach to professional learning, potentially capitalising on the inter-relationship between professional practice and learning through allowing each individual to tailor specific learning needs to their work demands. This paper describes one of the first studies examining professional learning in a MOOC. The study explores the learning behaviours of health professionals within Fundamentals Of Clinical Trials, a MOOC offered by edX. Through this research we have gained insight into how professionals learn within a MOOC environment. The study used self-regulated learning (SRL) as a theoretical lens, examining individual's learning behaviours across the three phases of SRL identified by Zimmerman (2000): forethought, performance, and self-reflection. The research questions were:

- RQ1: How do professionals prepare for learning in a MOOC? This question explores the motivations and expectations of professional learners as well as their goal setting and strategic planning during the forethought phase. 
- RQ2: What learning behaviours do professionals exhibit while learning in the MOOC? This question examines the ways professional learners interact with the course materials, other learners, and members of their professional network as they learn during the performance phase.

- RQ3: How do professionals relate their MOOC learning to their professional role? This question focuses on Zimmerman's self-reflection phase, questioning the perceived impact of the MOOC on an individual's professional practice.

The paper begins with a review of relevant literature on professional learning and learning in massive open online courses. Next, the course context is described, followed by a description of the methodology adopted and the sample studied. The study findings are then presented and the implications of these findings for research and practice are discussed.

\section{Review of Learning Literature}

Many professionals operate in settings where profound social and technological changes are fundamentally changing the nature of work (Dall'Alba, 2009, p. 4). Conventional forms of professional training are losing currency, particularly where they do not address critical dimensions of professional learning important for the contemporary workplace (Littlejohn \& Margaryan, 2013). First, job roles are becoming more specialized to the point that the learning required for a specific role has to be personalized. Conventional professional training, such as workshops and courses, is useful in allowing groups of people to reach a general level of competency. Nonetheless, these forms of training generally do not support bespoke learning. MOOCs potentially allow for personalized learning by giving professionals opportunity to align formalized learning with their practice, learning (via the network) with others who share similar and complementary experience and expertise. Their potential depends on how professionals align their personal learning goals with learning in the MOOC. Second, when work practice evolves continually, professionals constantly need to learn fresh knowledge to solve the new problems (Hager, 2004). Learning for work often blends deliberate, formalised learning with reactive, non-formal learning (Eraut, 2000). MOOCs open access to education, potentially offering a means by which professionals can continually update their knowledge. However, little is known about whether and how professionals learn in a MOOC environment and how this learning impacts upon their professional role. Third, when work roles are fluid and constantly changing, individuals continually have to draw upon existing knowledge across disciplinary or sectoral frontiers, connecting in ways that allow them to build new knowledge (Engeström, 2009). The knowledge professionals need to learn may be scientific (factual), experiential (practice based), socio-cultural or self-regulative (Tynjälä, 2008). Professionals need to be able to take greater responsibility for self-regulating their own professional learning, blending formal courses that tend to emphasise scientific 
knowledge, with non-formal opportunities from practice to learn experiential, sociocultural or self-regulative knowledge.

Self-regulation is the 'self-generated thoughts, feelings and actions that are planned and cyclically adapted to the attainment of personal goals' through three phases: forethought, performance and self-reflection (Zimmerman, 2000). Within these three phases, Zimmerman identified a number of sub-processes that self-regulating learners use, with more effective learners using a broader range of sub-processes. Each individual's ability to self-regulate their learning is context dependent, influenced by these personal dispositions as well as by factors associated with the environment in which he or she is learning. Some components of self-regulation are related to personal ability, while others are aligned with context.

One critical aspect of self-regulation, and of professional learning, is the ability to integrate different types of knowledge and expertise. Professional expertise has four basic components (Tynjälä \& Gijbels, 2012): factual knowledge which is based around conceptual or theoretical knowledge often codified in books, reports and other media sources; experiential knowledge which is difficult to codify and is often acquired through professional practice; self-regulative knowledge, focused on metacognition and 'knowing oneself'; and sociocultural knowledge, which is embedded in the social practices of groups and communities, providing a framework for interactions (Tynjälä \& Kallio, 2009). All four types of knowledge are critical for effective working. Conventional professional development and training focuses on factual knowledge, leaving professionals to develop their experiential, self-regulative and sociocultural knowledge through on-the-job practice. A critical element of each professional's selfregulated learning is to assimilate learning of all four types of knowledge through an 'integrative pedagogy' (Tynjälä \& Gijbels, 2012).

Another environment where learners must take an active role in managing their learning is a MOOC. MOOCs present a potentially useful mechanism for supporting and enabling professional learning, bringing diverse groups of learners together, united by common (or at least complementary and overlapping) learning needs. In this way, MOOCs could serve as a catalyst for the formation of heterogeneous learning communities that facilitate knowledge exchange. An underlying assumption is that learners have the skills and dispositions necessary to learn autonomously and socially within the MOOC. However, by definition, MOOCs attract a broad range of learners with diverse dispositions who differ in their ability to self-regulate their learning (Milligan, Littlejohn, \& Margaryan, 2013). There is evidence that learning strategies in MOOCs are influenced not only by learners' motivation and confidence, but also by the structure of the course, the delivery environment, and the perceived value of learning (Kop, 2011). Many authors have explored the impact of self-regulated learning skills on learner behaviour in formal, online courses (see Bernacki, Aguilar, \& Byrnes, 2011 for a comprehensive review). A clear link between self-regulated learning behaviours and learning success in online environments is established focusing on self-efficacy, interactions with others, and strategies for regulation. However, the strategies and 
behaviours needed for autonomous learning in MOOCs are not well understood (Liyanagunawardena, Adams, \& Williams, 2013). This gap in knowledge is of concern, given the recent rapid growth of MOOC initiatives (Daniel, 2012) from providers such as edX, Coursera, and FutureLearn.

\section{Context}

We explored the learning behaviours of health professionals studying the Fundamentals of Clinical Trials MOOC (https://www.edX.org/course/harvard-university/hsphhms214x/fundamentals-clinical-trials/941). The MOOC was designed by Harvard Medical School, Harvard School of Public Health, and Harvard Catalyst, The Harvard Clinical and Translational Science Center and offered through the edX initiative founded jointly between Harvard University and MIT. Our reason for selecting this MOOC was because a) the course was likely to attract a high number of participants working in the health domain, allowing us to examine how professionals learn and b) the course design was typical of the so-called 'xMOOCs' typified by the major MOOC providers (EdX, Coursera, Futurelearn). The MOOC provided an introduction to the scientific, statistical, and ethical aspects of clinical trials research. Each week, video lectures and course readings were presented, accompanied by a short automated assessment. To gain a certificate of completion, participants had to pass the assessments (80\%) and participate in two moderated case study discussions. The course was intended for individuals interested in conducting clinical trials who had foundations in epidemiology and biostatistics and attracted a combination of medical students and medical and health professionals. Over 22,000 learners registered for the course which ran from October 2013 until February 2014.

\section{Method}

A message posted to the course website in week 4 (of 12) of the course (November 2013) invited learners to participate in the study by initially completing an online survey instrument (http://tinyurl.com/srlmq). The survey instrument was designed to establish a self-regulated learning (SRL) profile for each study participant (not used in this analysis), as well as providing demographic data for the study. Gender, age, educational background and geographic distribution of the sample reflected the overall distribution of the course cohort as reported on the HarvardX insights pages (http://harvardx.harvard.edu/harvardx-insights). Participants who completed the survey instrument were invited to volunteer for a follow-up interview. Volunteers who also identified as a healthcare professional were then invited to participate in a semistructured interview exploring their learning within the MOOC in more detail. Interview questions were designed to explore learning behaviour according to the SRL phases and sub-processes as described by Zimmerman (2000). The interview script is available 
at http://tinyurl.com/plmooc-script. Thirty-five interviews (16 male and 19 female, from 23 countries) were conducted and recorded (via Skype) during December 2013 and J anuary 2014. Interviews were transcribed and stripped of identifying information. Transcripts were analysed and a combination of pre-defined and emergent codes used to categorise the data using the NViVO software package. Ethical standards for the study were adopted in accordance with local regulations and participants were free to withdraw at any point.

\section{Results}

\section{RQ1: How do Professionals Approach Learning in the MOOC?}

Forethought is critical to a learner's participation in a course. Zimmerman (2000) describes the forethought phase as the processes that occur before efforts to learn and comprise two key components - task analysis and planning processes, and selfmotivational processes. Motivation determines the amount of effort a learner will devote to learning, and his or her persistence when other priorities (e.g., work or family) compete for attention. Planning allows the learner to monitor their progress and adapt their learning as necessary. Therefore we collected data through questions focusing on motivation and goal setting.

The first interview question was 'Why did you sign up for this MOOC?' For around half the respondents (18/35: 51.4\%) participation was motivated by a desire to complement or formalise existing professional knowledge. This group included those who wished to maintain expertise as well as those who recognised that their prior learning had not prepared them adequately for their current role. One respondent who had originally trained as a medical doctor had changed roles. She described the gap in her knowledge as follows: "I work in a CRO (clinical research organisation) as a project manager, so [I'm familiar with clinical trials], but I don't carry a real fundamental background in this area" (respondent 24, project manager at clinical research organisation). The course attracted learners with a range of experience, from experts to people who were new in post. These people had noted immediate gaps in their knowledge that they needed to fill. A novice had signed up because he/ she needed new knowledge for her new job role: "I had recently been appointed as a pharmacist in clinical trials at the hospital I work at and of course I'd got this job but I didn't know a great deal about clinical trials" (256, pharmacist). An expert, with twelve years of experience noted an opportunity to fill gaps in knowledge: "... when I saw the syllabus of this training I was amazed because there are some things that I'm not very good at, like biostatistics etc. So there was a lot to learn for me" (373, clinical research consultant). Another group (10/35: 28.6\%) focused on longer term benefits. For them the course was less about filling an immediate knowledge gap and more about unlocking future career opportunities. A respondent 
from India understood how the course might help her expand her role: “... a lot of emphasis is being laid on research and I need to familiarise myself with clinical trials so that I myself can do research if possible" (226, consultant, department of medicine). While most respondents related their participation closely to a current or future role challenge, only one respondent reported that they were motivated by any broader value of the course, for example in providing opportunities to interact with professionals from other countries to learn about their context: "Well because I'm a researcher so it was a nice way to ... I don't know ... see how other countries function in this field most of all and also to refresh a little bit" (280, pharmacist). A few people had more general motivations that were not linked to professional learning, citing reasons including 'fun' or general interest (4/35: 11.4\%) or participating in a 'Harvard course' (3/35: 85.7\%).

Moving beyond learner motivation, we asked learners about their aims and goals. Most (26/35: 74.3\%) respondents described aims focused on new specific knowledge or skills they hoped to acquire; for example, "the aim was to gain knowledge about every step that is required in order to have a clinical study approved and then your drug put on the market: (78, medical doctor). Another response illustrates the learner making a link with their own practice: "my main aim is to get a basic grasp of critical concepts of clinical research, a history of different models of clinical trials designing and regulatory things that we have to abide by and the future prospect of clinical research" (128, research coordinator). Only one respondent highlighted a higher level aim focused on their broader professional practice: "I want to explore my knowledge in my professional field by gaining knowledge from this online course ... I will improve my knowledge and I will share my experiences with my colleagues and my juniors" (26, clinical data curator). Of the remainder, three articulated only vague aims based around their career, while five highlighted the attraction of gaining a certificate from Harvard.

While most respondents were readily able to summarise their aim, not all had set specific goals to guide their learning in the course. Goals are important to successful learning as they function to direct effort and define standards for successful completion (Sitzmann \& Ely, 2011). When asked whether they set specific goals at the beginning of the course, 11 (11/35: 31.4\%) respondents initially answered no (though most were able to articulate goals when prompted). Of the 24 who said they had set goals, the majority (17/24: $70.8 \%$ ) were focused on achieving a particular level of participation in the course such as "to attend all the lectures" (22, medical epidemiologist). Some had set an additional goal to gain the course certificate, though it was recognised that the main value of the certificate was personal. Only seven respondents articulated learning goals, focused on the topic of the course. Of these, only two had specific goals: "My goal was to be very confident of my fundamentals on probability, in statistics" (295, physician) and "to understand the statistics and clinical trials and data protection" (371, psychiatrist) while the remainder articulated learning goals that were categorised as vague, typified by, "to have an in depth knowledge of this area" (152, R\&D innovation projects coordinator). 


\section{RQ2: What Learning Behaviours do Professionals Exhibit while Learning in the MOOC?}

As well as understanding a learner's motivations and expectations, it is useful to build up a picture of how learners actually behave as they learn within the MOOC - what tools and learning strategies they are using and how they are interacting with other learners and their professional network. The second research question was explored through a number of questions relating to sub-processes of the performance phase of SRL described by Zimmerman (2000).

Respondents were first asked about the tools and resources they used to support their learning and how they used them. A small number (5/35: 14.3\%) focused only on using core course materials (videos and transcripts, and the course textbook): "I get very concentrated on the video content and the homework content and the assignments and whatever resource is needed to provide these assignments and I don't distract myself much more because ... of the time constraints" (152, R\&D innovation projects coordinator). All other respondents made use of the additional recommended resources, particularly the course eBook, and Wikipedia resources referred to during the course. All of this group also made use of other resources outside the course - the internet or their own books and pre-existing notes, however for most (21/30: 70\%), their use of resources beyond course materials was minimal and irregular (not routine). Only a small number (9/35: 25.7\%) of respondents described more extensive or specific strategies for augmenting their learning with this small group citing one or more specific external sources as forming a significant part of their learning on the course. Six respondents used Google Scholar or PubMed to explore primary scientific literature, while four made reference to YouTube as a source of alternative explanations, including one respondent who described how they integrated information from a range of sources:

... UCLA has a good statistics site, there are scholarly articles, Google Scholar has a number of things. Wikipedia is there, ...I go to YouTube and watch videos, like sometimes ... in my class I have not understood [a specific topic], so I go to YouTube and I try to see a few more videos on it and then I combine all these things, collate my understanding and come back now I have understood it. (295, physician)

Even among this group, the data indicates that exploring beyond the core course materials was not the norm.

We were interested to know whether study participants created their own resources while learning in the MOOC, as SRL research in online learning contexts has uncovered a link between students with sophisticated learning strategies (such as taking structured notes) and greater academic achievement (Kauffman, 2004). Almost half the respondents (16/35: 45.7\%) described making notes of some kind, either paper or 
electronic. Sometimes notes were integrated with the course materials: Seven respondents described how they downloaded and organised course materials and therefore had created their own resource library of course materials, while a further three respondents described making physical (paper) copies of course resources which they then annotated with their own notes. It is interesting to note that none of the respondents described maintaining a blog or sharing via twitter: Any materials created were solely for their own use. One study participant had shared resources through a Facebook group set up by some learners. Eleven respondents (11/35: 31.4\%) stated that they had not created any materials.

So far, the study has explored different ways in which the respondents have interacted with the course on their own. However learning is a social process and the MOOC includes opportunities for learners to communicate within the course forums. Even more significantly, as professionals, these learners have ready-made networks of colleagues with whom they may choose to discuss the course concepts. SRL research highlights the importance of interaction as a learning strategy adopted by successful learners in online contexts (Cho \& Kim, 2013), while workplace peers are recognised as a valuable source of learning support (Eraut, 2007). The next series of questions were designed to explore how respondents had interacted with other learners, with tutors, and with other members of their professional network. Within the course, the main mechanism for communication was the course discussion forum. Almost half (17/35: 48.6\%) of the respondents interacted in the discussion forum, either to discuss the course or share links they had found. The discussion forum received mixed responses. Some respondents were positive about the forum, recognising its value as a source of learning: "there were some candidates that were actually wonderful at giving explanations and in such detail and depth ... some of them are so, so good" (256, pharmacist). Another respondent, who used the forum daily, made a similar assertion:

My experience with the MOOC so far is equal learning, if not more, happens in the discussion forum. It is a great place and I make it a point that I visit the discussion board every single day, read through most of the posts which I can and try and participate/share my views as well. It's an amazing place. (295, physician)

However, negative attitudes were more common, with frustration at poor technical functionality and unanswered questions:

No one was helpful. Most of them didn't even understand what I meant at all, that was funny, I have tried 2 or 3 times to try and explain my problem and they couldn't understand me at all, I gave up and I really honestly don't have the time to spend so much time on the discussion board. (72, surgeon) 
A small number of respondents (7/35: 20\%) read the discussion forums but made a conscious decision not to contribute, choosing instead to lurk'. For some, this behaviour was motivated by time pressures: "But I go in the discussions and usually I find my answer within the discussions between the students. I don't get involved in the discussions because I know that time is limited" (152, R\&D innovation projects coordinator) while for others, lack of confidence was a barrier. A native Spanish speaker (forum discussions were in English) described his interaction in the forums as follows: "Not much really. I've seen this is more a personal limitation than course limitation. I don't feel very comfortable interacting just texting and expecting an answer" (249, neurologist).

As professionals, the learners in the study should already have networks of colleagues with whom they might discuss the course. This group can be particularly useful in translating the course materials into knowledge related to current practice. Colleagues provide local expertise that can help to personalise learning and, for non-English speakers, present an opportunity to think and discuss in one's own language. We were interested in the extent to which learners on the course discussed the content with their external networks. Around half of the respondents (17/35: 48.6\%) did speak to people outside the course, mainly to colleagues, while two respondents whose partners were also healthcare professionals also discussed with their spouses. When asked what they discussed, responses fell into two categories (some respondents mentioned both). The first category included those (13/35: 37.1\%) who passed on new knowledge from the course to others in their network: "I downloaded some videos and I sent them to some colleagues who are interested in clinical trials" (358, nurse) or who discussed the course content:

Yeah I have spoken about the course with my fellow colleagues who are working on the clinical trials with me in the capacity of coordinator ... have a good understanding of a critical concept and the history behind the research and different terms that affects this type of field, it's definitely going to help in my work and in the long run as well. (128, research coordinator)

A second group (8/35: 22.9\%) looked for support from their colleagues. For example one respondent discussed aspects they were unsure of with a colleague: "I [asked] another colleague of mine about some technical points in the course content, that's not related to my background" (28, physiotherapist) while another found new resources through friends: "I have friends who already have Masters with statistics, so they sent me videos to help me" (366, lecturer). Interactions with external networks that were reported appeared isolated, with no respondents reporting that they regularly or routinely discussed the course with their network, though there was one respondent who had signed up for the course with friends and colleagues whose contact was more regular: "normally when any of us have any difficulty we contact each other and share these, like in life or in a direct way" (249, neurologist). 


\section{RQ3: How do Professionals Relate their MOOC Learning to their Professional Role?}

The lasting value of professional learning comes when it can be applied back into practice. This study sought to explore how learners perceived the relation of course and practice by investigating the self-reflection behaviour of respondents. Learners were first asked whether they expected to integrate what they had learned into their professional practice. To this question, all respondents gave a positive response. Of course it should be highlighted that the interviews were conducted around halfway through the course; perhaps those who found little or no value in the course had already withdrawn. The majority (23/35: 65.7\%) saw the course as having a broad impact on their role, either immediately, "Well it gives me a better understanding of why I do what I do. ... I understand why I have to submit my protocol or a complete or total submission to authorities, how a protocol has been developed" (255, clinical trials project manager), or in the future:

I would like to move my career more in the research field. ... I work at an academic teaching and research institution ... and I know they're going to be building a research building soon, so I would like to move my career in that direction. (334, clinical pharmacist)

A smaller number (12/35: 34.3\%) were able to give more specific examples of how they expected to use their new knowledge immediately as the following example illustrates:

... right now we're doing some ethical committee issues and I saw those documents from United Kingdom and it's interesting because here in [my country] it's a little bit different, procedures and so on. ... it's also useful because if you have to collaborate with other countries you have to understand how [they] function, you have to adapt yourself. (280, pharmacist)

A similar question asked respondents to reflect on how their practice had changed as a result of the course. More than half (19/35: 54.3\%) felt the course had had an immediate impact on their practice. These respondents reported a range of general benefits: that the course had given them a new perspective, had made them assured, or had helped them bring a greater criticality to their practice. One respondent described her increased confidence: "I know why and why not ...you have an overview, I cannot say I apply everything in my day to day work, but the fact that you feel more confident, for me, it helps a lot" (255, clinical trials project manager). Another described a new perspective: "I guess it has changed in the way that one looks at some of the problems that you encounter at work and the solutions" (394, medical laboratory scientist). Even by half way through the course, some respondents were able to report direct changes to their practice: "It is much, much better, I could address all of the challenges much better 
and make better decisions and actually I participate with this CRO in developing the protocol and the study documents and everything"(152, R\&D innovation projects coordinator). As the course was still ongoing, some (11/35: 31.4\%) respondents felt that although they expected their practice to change, it had not done so yet. There was also some variation in what might constitute a practice change: While some participants described bringing new knowledge to bear on their decision making, others implied that while this might be so, constraints on their working practice meant that their actual practice would not change.

As well as understanding the link between the course and individual professional practice, the study sought to explore how learners valued the course. Respondents were asked whether they had talked to members of their professional network about the value (as opposed to the content) of the course or reflected on its value. Three respondents had talked to their manager about the course, as illustrated by the following quote: "We discussed already before I started whether it would be something that would be beneficial for my work" (143, epidemiologist). Only six respondents reported making any informal or formal record of their learning. These were primarily personal notes made alongside learning materials, but two respondents reported recording their learning formally for professional development; for example: "We have sort of an academic review that goes on every 6 months or so of our performance and this would be one of those things that I would put on that list of accomplishments" (360, otolaryngology resident). While not reflection, a large group (21/35: 60\%) had clearly seen value in the course, because they reported that they had recommended it to others. The enthusiasm of one respondent who encouraged a senior colleague to participate is clear: "I told him about the course he got very interested and he is in the process of joining it ... I just told him it's fantastic and you should not miss this opportunity and he is going to join" (226, consultant in department of medicine).

\section{Discussion and Conclusion}

This study surfaces some of the benefits and issues with MOOCs as a form of professional learning.

First, whether and how professionals align their professional goals with the aims of the course were examined through the research question, 'How do professionals prepare for learning in a MOOC?' Many of the professionals articulated their intention to align the MOOC with immediate or future (perceived) professional learning needs. However, their performance in the course focused on viewing and reading content and completing assessments in order to gain a certificate at the conclusion of the course. This switch in participants' focus from learning knowledge for specific work tasks to gaining a certificate highlights the mismatch between the type of learning for work inherent in informal, professional learning and formal for-credit learning. There was no evidence of professionals personalising course goals by linking theory to their professional practice. 
The learning behaviours of study participants were explored in detail through the second research question: What learning behaviours do professionals exhibit while learning in the MOOC?' Professionals tended to work on their own, reading and viewing pre-prescribed material. Study participants were focused on the core course materials. While most did also access additional resources, only a minority did this to any significant extent. Focusing effort on core course materials and activities is an effective strategy for achieving participation goals, but can result in a diminished learning experience as non-core aspects of the course, such as the exchange of ideas and experience that may occur in the discussion forum are neglected. There was little exchange of ideas and experience with the (massive numbers) of other participants and little evidence that learners were drawing on each other's experience. In this respect, the advantages afforded by networked learning seem to have been under-exploited. Around half of the study participants reported discussing course content with their external networks, to seek support or to explore ideas with trusted colleagues or relations. However as with accessing additional content, discussing the course content with external networks did not appear to be routine but rather driven by opportunity (chance meetings) or necessity (asking for support that was not available from the course tutors). These findings suggest that learners on this course are missing the opportunity to draw on the expertise of others participating in the MOOC. Professional learners bring a wealth of experience to their learning. Yet this experience remained (largely) untapped with little opportunity for learners to share their experience and build on their existing knowledge.

The third research question 'How do professionals relate their MOOC learning to their professional role?' explored the link between theory (in the MOOC) and practice (onthe-job). However the course did not promote or encourage the integration of the theory learned during the course with on-the-job practice. There were few examples of professionals linking the MOOC with their practice and almost no instances of practice change through participation in the course. Professionals placed little value on reflection on how the knowledge they learned on the course might impact their practice. A minority reflected on the value of the course with colleagues or individually. There were limited opportunities for learners to reflect on the knowledge gained from the course and how it may be embedded into their work practice before the end of the course. These findings illustrate the limitations of this type of course in improving professional practice. Yet the majority of participants reported they had learned about the ethics and statistical methods of clinical trials. Overall, the course was viewed positively by all respondents. Almost all professionals were active proponents for the course and there was evidence of extensive recommendation through external networks.

The use of a traditional course format for this MOOC appears to have limited its value as professional learning. Boud and Hager (2012) have highlighted the failings of professional development approaches that focus on certification and measurement, calling instead for professional learning to focus on individual needs, tightly integrated with work practice. To support professional learning, a MOOC could be designed along 
the principles of integrative pedagogy (Tynjälä \& Kallio, 2009) that explicitly sought to combine theory and practice, and to take advantage of the key attributes of professional learners. Professionals have precise learning needs, based on their role, background and motivations. A professional learning MOOC could encourage professional learners to take ownership of their learning by asking them to set personal goals, or at least personalise course goals that link theory to their own practice. The MOOC design could also exploit the existing knowledge of its professional learners as a core course resource. Professional learners bring a wealth of experience to their learning. Designing tasks which capitalise on this by encouraging the learners to build on existing knowledge and share their experience can enrich the learning experience for all by exposing learners to real world experience and new practices. Engaging with real world examples can be motivating and provides learners with evidence that they can use for their own personal development. Finally, a professional learning MOOC could support professional learners to reflect on the knowledge gained from the course and how it may be embedded into their work practice before the end of the course.

The findings presented here represent one aspect of a wider study exploring how design of MOOCs can foster professional learning. While this research contributes new empirical data collected there are some constraints. The key limitation is that the present study is based on data collected from a single course. While we are confident that our findings are broadly generalizable (it is likely learners in similarly designed MOOCs would display comparable behaviours), similar studies conducted in different contexts would strengthen these findings. The next phase of this study will explore the same research questions in a different MOOC context. In addition, the instruments developed for this study are publicly available for other researchers to repeat and refine our analysis in different courses. The qualitative nature of the data in this study also limits the conclusions that can be drawn from this work, but it is important to collect this type of data to enrich our understanding of learner behaviour in MOOCs. Although not presented here, our own study also collected quantitative data and our overall analysis will combine both types of data. A third limitation is the absence of any measure of successful professional learning in this study. Immediate impact on practice is likely to be limited, therefore longitudinal, ethnographic methods could provide greater insights.

\section{Acknowledgements}

This study was part of the MOOC Research Initiative led by Athabasca University and supported by a grant from the Bill \& Melinda Gates Foundation. We are grateful to the Fundamentals of Clinical Trials course team for providing access and assistance, particularly Ms Obiageli Ukadike. We thank Ms Lou McGill for conducting interviews and the study participants for their time. 


\section{References}

Beckett, D. \& Hager, P. J . (2002). Life, work and learning: Practice in postmodernity. London: Routledge.

Bernacki, M. L., Aguilar, A., \& Byrnes, J . (2011). Self-regulated learning and technologyenhanced learning environments: An opportunity propensity analysis. In G. Dettori \& D. Persico (Eds.), Fostering self-regulated learning through ICT (pp. 1-26). Hershey, PA: IGI Global Publishers.

Boud, D., \& Hager, P.(2012). Re-thinking continuing professional development through changing metaphors and location in professional practices. Studies in Continuing Education, 34(1) 17-30.

Cho M-H., \& Kim, B. J . (2013). Students' self-regulation for interaction with others in online learning environments. The Internet and Higher Education, 17(1), 69-75.

Dall' Alba, G. (2009). Learning to be professionals. Innovation and change in professional education (Vol. 4). Dordrecht: Springer.

Daniel, J . (2012). Making sense of moocs: Musings in a maze of myth, paradox and possibility. J ournal of Interactive Media In Education, 3(0). Retrieved August 8, 2013, from http:// www-jime.open.ac.uk/jime/ article/ view/ 2012-18.

Engeström, R. (2009). Who is acting in an activity system? In A. Sannino, H. Daniels, \& K. D. Gutiérrez (Eds.), Learning and expanding with activity theory (pp. 257273). New York, NY: Cambridge University Press.

Eraut, M. (2000). Non-formal learning and tacit knowledge in professional work. British J ournal of Educational Psychology, 70(1), 113-136.

Eraut, M. (2007). Learning from other people in the workplace. Oxford Review of Education, 33(4), 403-422.

Hager, P. (2004). The conceptualization and measurement of learning at work. In $\mathrm{H}$. Rainbird, A. Fuller, \&A. Munro. (Eds.), Workplace learning in context (pp 242258). London: Routledge.

J ones, C., \& Steeples, C. E. (2002) Networked learning: Perspectives and issues. In C. J ones and C.E. Steeple (Eds.) Perspectives and issues in networked learning: Computer supported cooperative work (pp. 1-14). Springer: London.

Kauffman, D. F. (2004). Self-regulated learning in web-based environments: Instructional tools designed to facilitate cognitive strategy use, metacognitive processing, and motivational beliefs. J ournal of Educational Computing Research, 30(1), 139- 161. 
Kop, R. (2011). The challenges to connectivist learning on open online networks: learning experiences during a massive open online course. The International Review of Research in Open and Distance Learning, 12 3), 19-38.

Littlejohn, A., Milligan, C., \& Margaryan, A. (2011). Collective learning in the workplace: Important knowledge sharing behaviours. International J ournal of Advanced Corporate Learning, 4(4) 26-31.

Littlejohn, A., \& Margaryan, A. (2013). Technology enhanced professional learning: Mapping out a new domain. In Littlejohn, A., \& Margaryan, A. (Eds.). Technology-enhanced professional learning: Processes, practices and tool (pp1-13). London, Routledge.

Liyanagunawardena, T. R., Adams, A. A., \&Williams, S. A. (2013). MOOCs: A systematic study of the published literature 2008-2012. International Review of Research in Open and Distance Learning, 14(3) 202-227.

Milligan, C., Littlejohn, A., \& Margaryan, A. (2013). Patterns of engagement in connectivist MOOCs. J ournal of Online Learning \& Teaching, 9(2) 149-159.

Sitzmann, T., \& Ely, K. (2011). A meta-analysis of self-regulated learning in work-related training and educational attainment: What we know and where we need to go. Psychological Bulletin, 137(3), 421-442.

Tynjälä, P. (2008). Perspectives into learning in the workplace. Educational Research Review, 3(2), 130-154.

Tynjälä, P. \& Gijbels, D. (2012). Changing world: Changing pedagogy. In P. Tynjälä, Stenström, M-L and Saarnivaara, M. (Eds.), Transitions and transformations in learning and education (pp 205-222). Dordrecht: Springer.

Tynjälä, P., \& Kallio, E. (2009). Integrative pedagogy for developing vocational and professional expertise. Paper presented at the 13th Biennial Conference for Learning and Instruction, Amsterdam, Netherlands.

Zimmerman, B. J . (2000). Attaining self-regulation: A social cognitive perspective. In M. Boekaerts, P.R. Pintrich \& M. Zeidner (Eds.), Handbook of self-regulation (pp. 13-39). San Diego, CA: Academic Press. 
(C) Milligan and Littlejohn

\section{Athabasca University $\mathbf{a}$}

(c) (†)

This work is licensed under a Creative Commons Attribution 4.0 International License. 